\title{
Observations on the pattern on biohydrogenation of esterified and unesterified linoleic acid in the rumen
}

\author{
By R. C. NOBLE, J. H. MOORE AND C. G. HARFOOT \\ Hannah Research Institute, Ayr KA6 5 HLL
}

(Received I4 May г973-Accepted I6 fuly I973)

\begin{abstract}
I. Studies have been made of the effects of different concentrations of either free or esterified linoleic acid on the biohydrogenation of linoleic acid by rumen micro-organisms in vitro. A comparison has been made with the changes which occurred in the fatty acid compositions of rumen free fatty acids and plasma triglycerides of sheep given intraruminal infusions of linoleic acid or maize oil.

2. In the in vitro experiments, with increasing concentrations of $18: 2$ added as the free fatty acid, a decreasing proportion of this $18: 2$ was hydrogenated to $18: 0$ and trans-I I-octadecenoic acid accumulated. The accumulation of large amounts of trans-II-octadecenoic acid was accompanied in all instances by the accumulation of a conjugated diene identified as cis- 9 , trans-II-octadecadienoic acid. There appeared to be a product-precursor relationship between the conjugated diene and the trans-I I monoene.

3. When linoleic acid was presented in vitro as the triglyceride, the extent to which hydrogenation occurred was, in all instances, greater than when equivalent amounts of $18: 2$ were presented as the free acid. Only small amounts of the cis-9, trans-I I diene were detected, and there was no apparent product-precursor relationship between this conjugated diene and the $\mathrm{C}_{18}$ monoenoic acids. 'The $\mathrm{C}_{18}$ monoenoic acids that accumulated consisted of both $c$ is and trans isomers; the cis isomers consisted largely of cis-9-and cis-1 I-octadecenoic acids, which together comprised about $30 \%$ of the $\mathrm{C}_{18}$ monoenoic acids present.

4. The infusion of free linoleic acid into the rumen of sheep resulted in an increase in the proportion of total $18: 1$ and a decrease in the proportions of $16: 0$ and $18: 0$ in the total rumen free fatty acids. This increase which occurred in the concentration of $18: 1$ consisted predominantly of the trans-II isomer. A concomitant increase in the concentration of the $\mathrm{C}_{18}$ trans-I I acid was observed to occur in the fatty acids of the plasma triglycerides. Infusion of maize oil into the rumen of sheep resulted in little change in the fatty acid compositions of either the free fatty acids in the rumen or the triglycerides of the plasma.

5. The findings in vitro and in vivo are discussed with reference to each other and with reference to the possibility that biohydrogenation of $18: 2$ derived from the triglyceride proceeds by a different pathway from that of $18: 2$ presented as the free acid.
\end{abstract}

The ability of the micro-organisms present in the rumen to hydrogenate $C_{18}$ unsaturated fatty acids is now well documented and has been the subject of several recent reviews (Garton, r965; Dawson \& Kemp, r969; Viviani, 1970). However, work from our laboratory has shown that the efficiency with which rumen organisms are able to hydrogenate unsaturated fatty acids depends on whether these acids are presented as substrates in the free or esterified form (Noble, Steele \& Moore, I969). Thus when trilinolein was infused into the rumen of a sheep, there was a transient increase in the concentration of linoleic acid in the rumen contents and this was followed by an increase in the concentration of stearic acid. However, when an equivalent amount of free linoleic acid was infused into the rumen, the transient increase in the concentration of linoleic acid was followed by an accumulation of octadecenoic acid in the rumen contents with little or no production of stearic acid. In experiments in which equivalent amounts of free or esterified linoleic acid 
have been incubated with rumen liquor in vitro (Moore, Noble, Steele \& Czerkawski, 1969), the differences in the pattern of hydrogenation observed were similar to those observed in vivo (Noble et al. 1969 ).

It has been shown by Ward, Scott $\&$ Dawson (1964) that an important intermediate in the hydrogenation of the $C_{18}$ polyunsaturated fatty acids in the rumen is the $C_{18: 1}$ trans-I I isomer. This isomer is characteristically found in the tissues of ruminant animals (Dawson \& Kemp, 1969). Normally the amounts found are small. However, it has been shown that, when dairy cows are given a diet containing a high proportion of $\mathrm{C}_{18}$ polyunsaturated fatty acids which are readily accessible to the rumen microorganisms, the concentration of this trans-I I monoene may undergo a significant increase in both the tissues and milk fat (Steele, Noble \& Moore, I97I; Macleod, Wood \& Yao, 1972).

In the investigation now reported, a study has been made of the effects of different concentrations of either free or esterified substrate on the biohydrogenation of linoleic acid by rumen micro-organisms in vitro, and analyses have been made of the isomers produced as intermediates in the biohydrogenation process. The results of this investigation have been compared with the changes in the fatty acid composition of the rumen free fatty acids and plasma triglycerides of sheep receiving intraruminal infusions of similar substrates.

\section{EXPERIMENTAL}

\section{Animals and diet}

Three adult wether sheep of the Suffolk breed each fitted with a permanent rumen fistula and weighing about $65 \mathrm{~kg}$ were housed in individual metabolism cages. The sheep were given $0.5 \mathrm{~kg}$ sugar-beet pulp $+0.5 \mathrm{~kg}$ hay $/ \mathrm{d}$ in two equal portions, one at 09.00 hours and the other at 16.00 hours. Water was given ad lib. The sheep were given the diet for $28 \mathrm{~d}$ before samples of rumen contents were taken and for the remainder of the experiment.

\section{Procedures}

Experiments in vitro. In all experiments the artificial rumen system of Czerkawski \& Breckenridge (1969) was used. The gas phase consisted of $5 \% \mathrm{CO}_{2}$ in $\mathrm{N}_{2}$ and was continuously recycled through the rumen contents. Strained rumen contents were obtained from the three fistulated sheep on day 29; representative samples from each animal were pooled for each incubation. Each incubation vessel contained $200 \mathrm{ml}$ of buffer solution (McDougall, 1948 ) and $100 \mathrm{ml}$ of water containing $\mathrm{I}_{5} \cdot \mathbf{g}$ sucrose and $200 \mathrm{mg}\left(\mathrm{NH}_{4}\right)_{2} \mathrm{CO}_{3}$. After the apparatus had been gassed for $30 \mathrm{~min}$ with $5 \% \mathrm{CO}_{2}$ in $\mathrm{N}_{2}, 200 \mathrm{ml}$ of the strained rumen contents were added to each vessel. Each vessel was incubated for $30 \mathrm{~min}$ before addition of the appropriate lipid. All incubations were done at $39^{\circ}$ and samples of the reaction mixture were taken from each vessel at various times (see Table 2) after the addition of substrate. The initial $\mathrm{pH}$ of each incubation vessel was $7 \cdot 2$.

All lipids used as substrates were obtained from Sigma (London) Chemical Co., 
Kingston-upon-Thames, UK, and were added to the appropriate incubation vessels as emulsions in $20 \mathrm{ml}$ of a r \% (v/v) aqueous solution of Tween 80 (polyoxyethylene sorbitan mono-oleate; Honeywill \& Stein Ltd, London). In Expt $\mathrm{I}$, three concentrations of linoleic acid ( $99 \%$ pure) were used: $0.32,0.65$ and $0.97 \mathrm{mg} / \mathrm{ml}$ strained rumen contents (64, 130 and $194 \mathrm{mg} /$ vessel respectively). In Expt 2, three concentrations of trilinolein (99\% pure) were used: $0.46,0.90$ and $\mathrm{r} \cdot 33 \mathrm{mg} / \mathrm{ml}$ strained rumen contents $(98,180$ and $266 \mathrm{mg} / \mathrm{vessel}$ respectively); these concentrations correspond to $0.44,0.86$ and $\mathrm{x} .27 \mathrm{mg}$ linoleic acid/ml rumen contents respectively. In each experiment, control vessels contained $20 \mathrm{ml}$ of a $\mathrm{i} \%(\mathrm{v} / \mathrm{v})$ aqueous solution of Tween 80 .

Experiments in vivo. After the morning feed on the 39 th day, an emulsion of $40 \mathrm{~g}$ of 'linoleic acid' ( $15 \cdot 2 \%$ I6:0, $0.3 \%$ I6: I, $2 \cdot 2 \%$ I $8: 0,10 \cdot 9 \%$ I $8: 1$ and $71 \cdot 1 \%$ I $8: 2$; Prices, Bromborough Ltd, Bebington, Cheshire) in Tween 80 was infused at constant rate into the rumen of each sheep between 10.00 and 11.00 hours. The emulsion was prepared and infused by the method of Moore, Noble \& Steele (1968). With the apparatus described by Czerkawski (I966), samples of rumen contents were taken from the sheep immediately before infusion and $24 \mathrm{~h}$ after the infusion. Blood samples $(3 \circ \mathrm{ml})$ were taken from the jugular vein of each sheep by means of Vacutainer tubes (Becton Dickinson, New Jersey, USA) before the infusion and $24 \mathrm{~h}$ after the infusion had begun. Ten days later (i.e. on the $49^{\text {th }}$ day) an emulsion of $40 \mathrm{~g}$ maize oil (containing 9.9\% 16:0, 2.1 \% I $8: 0,22.9 \%$ I8: $1,0.7 \%$ I $8: 3$ and $64.4 \%$ I8:2) in Tween 80 was infused into the rumen of each sheep, and blood and rumen samples were taken immediately before the infusion and $24 \mathrm{~h}$ after the infusion had begun.

\section{Analytical procedures}

The lipids were extracted from the samples of plasma by the method of Nelson \& Freeman (1959) and from the samples of rumen contents and incubation mixtures by the method of Moore \& Williams ( 1963$)$. The extracted lipids were separated by thin-layer chromatography on glass plates coated with Kieselgel G (E. Merck AG, Darmstadt, Germany); the solvent system was hexane-diethyl ether-formic acid (80:20:1, by volume). The fatty acid compositions of the various lipid fractions were determined by gas-liquid chromatographic procedures described in detail by Moore \& Williams ( 1966$)$ and, when applicable, their concentrations were determined by the addition to each fraction of a known amount of $n$-heptadecanoic acid as an internal standard (Christie, Noble \& Moore, 1970). By these procedures, recoveries of standard amounts of lipids were between 95 and $105 \%$.

The octadecenoic acids from the unesterified fatty acid fractions of the rumen contents and from the triglyceride fraction of the plasma were further separated into total cis and total trans isomers by thin-layer chromatography on silica gel impregnated with $\mathrm{AgNO}_{3}$ (Morris, I966). The proportions of the positional isomers in each of the fractions were determined with a gas-liquid chromatograph fitted with a single flame-ionization detector and a support-coated, open capillary column $(0.5 \times 15250 \mathrm{~mm})$ containing a stationary phase of diethylene glycol succinate (Perkin-Elmer Ltd, Beaconsfield, England). The retention volumes of the isomers 


\section{Table r. Expt r. In vitro hydrogenation of linoleic acid incubated with rumen contents of sheep}

\begin{tabular}{|c|c|c|c|c|c|c|c|c|c|}
\hline \multirow{2}{*}{$\begin{array}{c}\text { Initial } \\
\text { concentration of } \\
\text { 8:2 (mg/ml rumen } \\
\text { contents) }\end{array}$} & \multirow[b]{2}{*}{$\mathrm{C}_{1 \mathrm{~g}}$ acid } & \multicolumn{8}{|c|}{ Incubation time (h) } \\
\hline & & 0 & 0.2 & 0.5 & I.O & $2 \cdot 0$ & $3 \cdot 0$ & $5 \cdot 0$ & $7 \cdot 0$ \\
\hline 0.32 & $\begin{array}{l}\text { I8:0 } \\
\text { I 8: I trans-I I } \\
\text { 18:2 cis-9, trans-I I } \\
\text { 18:2 cis-9, cis-12 }\end{array}$ & $\begin{array}{c}0 \\
0 \\
0 \\
323 \cdot 1\end{array}$ & $\begin{array}{r}9^{\cdot 1} \\
53 \cdot 2 \\
140^{\circ} 0 \\
121 \cdot 2\end{array}$ & $\begin{array}{r}25 \cdot 1 \\
233 \cdot 0 \\
12 \cdot 7 \\
52 \cdot 3\end{array}$ & $\begin{array}{r}66 \cdot 2 \\
248 \cdot 1 \\
8 \cdot 2 \\
0\end{array}$ & $\begin{array}{l}162 \cdot 5 \\
\times 53 \cdot 1 \\
8 \cdot 0 \\
0\end{array}$ & $\begin{array}{c}195 \cdot 6 \\
\text { I } 22 \cdot 1 \\
6 \cdot 2 \\
0\end{array}$ & $\begin{array}{r}230 \cdot 8 \\
86 \cdot 5 \\
5 \cdot 1 \\
0\end{array}$ & $\begin{array}{r}254 \cdot 7 \\
73 \cdot 6 \\
5 \cdot 2 \\
0\end{array}$ \\
\hline 0.65 & $\begin{array}{l}18: 0 \\
18: 1 \text { trans-1 } 1 \\
18: 2 \text { cis-9, trans-I } 1 \\
18: 2 \text { cis }-9, \text { cis-12 }\end{array}$ & $\begin{array}{c}0 \\
0 \\
0 \\
6457\end{array}$ & $\begin{array}{r}55 \cdot 8 \\
42 \cdot 3 \\
127 \cdot 9 \\
420 \cdot 2\end{array}$ & $\begin{array}{r}62 \cdot 9 \\
148 \cdot 4 \\
322 \cdot 9 \\
111 \cdot 3\end{array}$ & $\begin{array}{r}66 \cdot 0 \\
332 \cdot 1 \\
236 \cdot 8 \\
10 \cdot 1\end{array}$ & $\begin{array}{r}85 \cdot 1 \\
535 \cdot 7 \\
16 \cdot 0 \\
8 \cdot 1\end{array}$ & $\begin{array}{r}127 \cdot 9 \\
502 \cdot 7 \\
6 \cdot 1 \\
8 \cdot 4\end{array}$ & $\begin{array}{c}276 \cdot 1 \\
408 \cdot 0 \\
0 \\
11 \cdot 2\end{array}$ & $\begin{array}{c}302 \cdot 3 \\
333 \cdot 8 \\
0 \\
9 \cdot I\end{array}$ \\
\hline 0.97 & $\begin{array}{l}\text { I8:0 } \\
\text { I8: } 1 \text { trans-I I } \\
\text { I } 8: 2 \text { cis- } 9, \text { trans-I I } \\
\text { I8:2 cis-9, cis- } 12\end{array}$ & $\begin{array}{c}0 \\
0 \\
0 \\
968 \cdot 3\end{array}$ & $\begin{array}{r}53^{\circ} 9 \\
29^{\circ} 1 \\
174^{\circ} 1 \\
710.9\end{array}$ & $\begin{array}{r}66 \cdot 0 \\
109 \cdot 3 \\
566 \cdot 2 \\
226 \cdot 9\end{array}$ & $\begin{array}{r}78 \cdot 1 \\
232 \cdot 4 \\
616 \cdot 0 \\
41 \cdot 1\end{array}$ & $\begin{array}{r}86 \cdot 8 \\
471 \cdot 7 \\
380 \cdot 2 \\
28 \cdot 9\end{array}$ & $\begin{array}{r}103.2 \\
619.3 \\
230.9 \\
15.0\end{array}$ & $\begin{array}{r}\text { I } 14 \cdot 2 \\
749^{\circ} \cdot 1 \\
88 \cdot 2 \\
16 \cdot 2\end{array}$ & $\begin{array}{r}120.0 \\
790.8 \\
38.0 \\
19.3\end{array}$ \\
\hline
\end{tabular}

were identified by the use of authentic acids obtained from the Hormel Institute (Austin, Minnesota, USA). The positional distribution of the double bonds was further checked by oxidation of the methyl ester fractions (Chang \& Sweeley, 1962) and resultant mono- and dicarboxylic acids were analysed by the gas-liquid chromatographic method of Moore \& Williams ( 1966 ). Whenever possible, reactions were carried out under $\mathrm{N}_{2}$ and 2,6-di-t-butyl-p-cresol was added to the thin-layer chromatographic sprays to minimize oxidation. Solvents were distilled before use.

\section{RESULTS}

\section{Experiments in vitro}

Expt I. The fatty acid compositions of the unesterified fatty acid fraction of the incubation mixture following the incubation of $0.32,0.65$ and $0.97 \mathrm{mg}$ of linoleic acid $/ \mathrm{ml}$ strained rumen contents are shown in Table I. The values are corrected for the control vessel to which no linoleic acid was added and are expressed as $\mathrm{mg} \mathrm{C}_{18}$ fatty acid/1 rumen contents. The concentration ( $\mathrm{mg} / \mathrm{ml}$ rumen contents) and the fatty acid composition of the unesterified fatty acid fraction of the reaction mixture in the control vessel remained constant throughout the incubation period. The concentrations of the major fatty acids in the control vessel were $(\mathrm{mg} / \mathrm{ml}$ strained rumen contents): $16: 0,0.02 ; 18: 0,0.08 ; 18: 1,0.01$; others $\left(\mathrm{C}_{15}\right.$ and $\left.\mathrm{C}_{17}\right)$, 0.01 . The proportions in which these fatty acids were present were: $16: 0,17 \%$; $\mathrm{r} 8: 0,65 \% ; \mathrm{r} 8: \mathrm{x}, 9 \%$; others $\left(\mathrm{C}_{15}\right.$ and $\left.\mathrm{C}_{17}\right), 9 \%$. This is similar to the fatty acid composition of the lipids found in strained rumen contents under normal conditions (Viviani, $197^{\circ}$ ). With the addition of $18: 2$, there was a marked and rapid accumulation of the $\mathrm{C}_{18}$ monoenoic acid and a decrease in the relative concentration of stearic acid.

With the incubation of $0.32 \mathrm{mg} 18: 2 / \mathrm{ml}$ rumen contents, the $\mathrm{C}_{18}$ monoenoic acid 


\section{Table 2. Expt I. In vitro hydrolysis of tritinolein incubated with rumen contents of sheep}

\begin{tabular}{|c|c|c|c|c|c|c|c|c|c|}
\hline \multirow{2}{*}{$\begin{array}{l}\text { Initial concentration } \\
\text { of trilinolein }(\mathrm{mg} / \mathrm{ml} \\
\text { rumen contents) }\end{array}$} & \multirow{2}{*}{$\begin{array}{l}\text { Lipid component } \\
\text { estimated. }\end{array}$} & \multicolumn{8}{|c|}{ Incubation time (h) } \\
\hline & & $\circ$ & 0.2 & 0.5 & $I \cdot 0$ & $2 \cdot 0$ & 3.0 & $5 \cdot 0$ & $7 \cdot 0$ \\
\hline 0.46 & $\begin{array}{l}\text { Triglyceride } \\
\text { Partial glycerides* } \\
\text { Unesterified fatty acids }\end{array}$ & $\begin{array}{c}100 \\
0 \\
0\end{array}$ & $\begin{array}{r}85 \cdot 6 \\
10 \cdot 1 \\
4 \cdot 3\end{array}$ & $\begin{array}{r}76 \cdot 0 \\
7 \cdot 2 \\
16 \cdot 8\end{array}$ & $\begin{array}{r}59 \cdot 7 \\
5 \cdot 8 \\
34 \cdot 5\end{array}$ & $\begin{array}{r}39 \cdot 6 \\
5 \cdot 6 \\
54 \cdot 8\end{array}$ & $\begin{array}{r}26 \cdot 1 \\
2 \cdot 7 \\
71 \cdot 2\end{array}$ & $\begin{array}{r}I I \cdot 2 \\
I \cdot 7 \\
87 \cdot I\end{array}$ & $\begin{array}{c}0 \\
0.9 \\
99 \cdot 1\end{array}$ \\
\hline 0.90 & $\begin{array}{l}\text { Triglyceride } \\
\text { Partial glycerides* } \\
\text { Unesterified fatty acids }\end{array}$ & $\begin{array}{c}100 \\
0 \\
0\end{array}$ & $\begin{array}{r}93 \cdot \mathbf{I} \\
4 \cdot 1 \\
2 \cdot 8\end{array}$ & $\begin{array}{r}82 \cdot 7 \\
8 \cdot 5 \\
8 \cdot 8\end{array}$ & $\begin{array}{l}64 \cdot 0 \\
13 \cdot 9 \\
22 \cdot 1\end{array}$ & $\begin{array}{r}44 \cdot 4 \\
6 \cdot 3 \\
49 \cdot 3\end{array}$ & $\begin{array}{r}25 \cdot 9 \\
6 \cdot 0 \\
68 \cdot 1\end{array}$ & $\begin{array}{r}6 \cdot 7 \\
3 \cdot 1 \\
90 \cdot 2\end{array}$ & $\begin{array}{c}0 \\
I \cdot 6 \\
98 \cdot 4\end{array}$ \\
\hline I. 33 & $\begin{array}{l}\text { Triglyceride } \\
\text { Partial glycerides* } \\
\text { Unesterified fatty acids }\end{array}$ & $\begin{array}{c}100 \\
0 \\
0\end{array}$ & $\begin{array}{r}93 \cdot 6 \\
3 \cdot 0 \\
3 \cdot 4\end{array}$ & $\begin{array}{r}88 \cdot 2 \\
6 \cdot 0 \\
6 \cdot 8\end{array}$ & $\begin{array}{r}78.6 \\
6.7 \\
14.7\end{array}$ & $\begin{array}{r}59 \cdot 8 \\
9.9 \\
30 \cdot 3\end{array}$ & $\begin{array}{r}46 \cdot 1 \\
7 \cdot 8 \\
46 \cdot 1\end{array}$ & $\begin{array}{r}24.0 \\
2.6 \\
73.4\end{array}$ & $\begin{array}{r}9 \cdot 9 \\
I \cdot 5 \\
88 \cdot 6\end{array}$ \\
\hline
\end{tabular}

concentration reached a maximum only $\mathrm{I} h$ after the start of incubation. At the completion of incubation $76 \%$ of the added $18: 2$ had been converted into $18: 0$, and $22 \%$ still remained as the $\mathrm{C}_{18}$ monoenoic acid. With the incubation of $0.65 \mathrm{mg}$ $\mathrm{r} 8: 2 / \mathrm{ml}$ rumen contents, a maximum concentration of $\mathrm{C}_{18}$ monoenoic acid was reached $2 \mathrm{~h}$ after incubation had begun. At the completion of incubation, $46 \%$ of the added $18: 2$ had been converted into $18: 0$, and $52 \%$ remained as the monoenoic acid. When $0.97 \mathrm{mg} \mathrm{I} 8: 2 / \mathrm{ml}$ rumen contents was incubated a maximum concentration of the $\mathrm{C}_{18}$ monoenoic acid occurred after $5 \mathrm{~h}$. At the completion of incubation, only about $12 \%$ of the added $18: 2$ had been converted into $18: 0 ; 82 \%$ of the added 18:2 remained as the $C_{18}$ monoenoic acid. The $C_{18}$ monoenoic acid fraction that accumulated was identified in all instances as being composed entirely of the trans-I I isomer.

The accumulation of large amounts of trans-II-octadecenoic acid was preceded in all instances by the accumulation of a conjugated diene which was identified as the cis-9, trans-11-octadecadienoic acid. There appeared to be a product-precursor relationship between the conjugated diene and the trans-I I monoene. The accumulation of this conjugated diene increased with the increasing initial concentration of $18: 2$ and could be associated with the decrease in the rate of appearance of $18: \mathrm{I}$.

Expt 2. The products of hydrolysis when $0.46,0.90$ and $\times 33 \mathrm{mg}$ trilinolein $/ \mathrm{ml}$ rumen liquor were incubated are shown in Table 2. At all three initial substrate concentrations the hydrolysis of trilinolein was fairly rapid, with some accumulation of mono- and diglycerides.

The fatty acid compositions of the unesterified fatty acid fractions produced as a result of incubating $0.46,0.90$ and $1.33 \mathrm{mg}$ trilinolein $/ \mathrm{ml}$ rumen liquor are shown in Table 3. The values are again corrected for the control vessel to which no trilinolein was added and are expressed as $\mathrm{mg}$ fatty acid/l rumen contents. The fatty acid composition of the triglyceride fraction remained constant throughout incubation, 
Table 3. Amounts of $C_{18}$ fatty acids derived from linoleic acid released by in vitro hydrolysis of trilinolein with rumen contents of sheep

(Values are corrected for control values (no added trilinolein) and

Initial

substrate concentration

( $\mathrm{mg}$ trilinolein/ml

rumen contents)

$0 \cdot 46$

0.90

1.33 are expressed as ing fatty acid/l rumen contents)

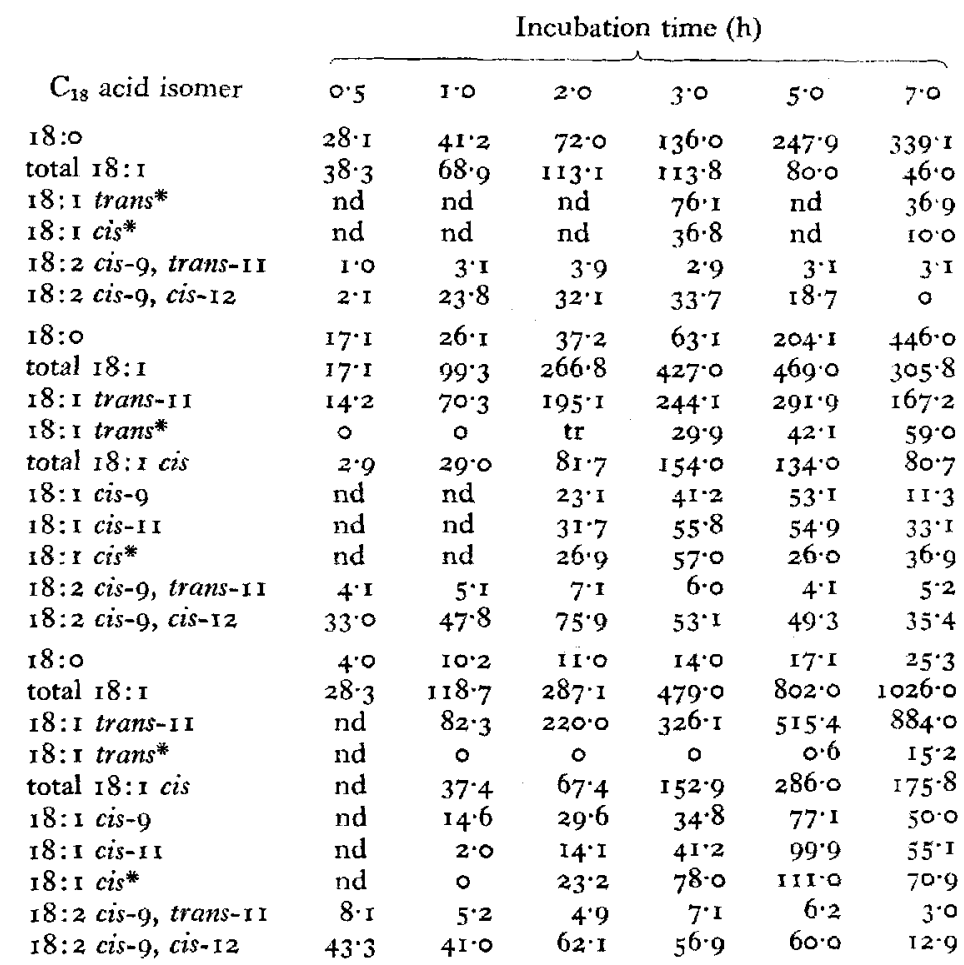

nd, not determined; tr, trace amount present.

* Insufficient material to allow determination of double bond position.

indicating that no hydrogenation occurred without prior hydrolysis of the triglyceride. With increasing concentrations of added trilinolein, the hydrogenation of linoleic acid was both slower and less complete. At none of the concentrations of trilinolein used did more than $5 \%$ of the $18: 2$ added remain unhydrogenated at the end of incubation. When $0.44 \mathrm{mg}$ of $18: 2 / \mathrm{ml}$ strained rumen contents was added in the form of trilinolein, $77 \%$ of the $18: 2$ was converted into $18: 0,10.5 \%$ remaining as $\mathrm{I} 8: \mathrm{I}$. When $0.86 \mathrm{mg}$ of $\mathrm{I} 8: 2 / \mathrm{ml}$ rumen contents was used, $51.9 \%$ was converted into $18: 0,35.6 \%$ remaining as $18: 1$. At the highest concentration of trilinolein ( $\mathrm{x} \cdot 27 \mathrm{mg} \mathrm{I} 8: 2 / \mathrm{ml}$ rumen contents), only $2 \cdot 0 \%$ of the $18: 2$ was hydrogenated to $\mathrm{I} 8: 0$ and $80.8 \%$ remained as $\mathrm{I} 8: \mathrm{I}$ at the end of incubation.

The cis-9, trans-I I conjugated diene produced when $18: 2$ was added as trilinolein to strained rumen contents was only present in small amounts (cf. Table I); in most instances it accounted for less than $3 \%$ of the total $18: 2$ added to the incubation mixture. There was no apparent product-precursor relationship between the cis-9, trans-I I conjugated diene and the total concentration of the $\mathrm{C}_{18}$ monoenoic acids. 
Table 4. Percentage compositions of the main fatty acids of rumen free fatty acids and plasma triglycerides of sheep before and $24 \mathrm{~h}$ after intraruminal infusion of 'linoleic acid'

\begin{tabular}{|c|c|c|c|c|}
\hline Fatty acid* & Before infusion & After infusion & Before infusion & After infusion \\
\hline I6:0 & $16 \cdot 7$ & $9: 2$ & 257 & $17 \cdot 3$ \\
\hline 18:0 & $74 \cdot 2$ & $4 I \cdot 7$ & $39 \cdot 3$ & $26 \cdot 3$ \\
\hline Total $18: 1$ & $8 \cdot 6$ & $44 \cdot I$ & $27 \cdot 1$ & $52 \cdot 0$ \\
\hline 18: I cis-9 & $2 \cdot 6$ & $7 \cdot 5$ & 20.0 & $2 x \cdot 8$ \\
\hline 18: I trans-1 I & $6 \cdot 0$ & $36 \cdot 6$ & $4 \cdot 5$ & $26 \cdot 8$ \\
\hline$x 8: 2$ & 0.5 & 5.0 & 41 & $3 \cdot 7$ \\
\hline $18: 3$ & $t$ & + & $3 \cdot 8$ & 0.7 \\
\hline
\end{tabular}

The $\mathrm{C}_{18}$ monoenoic acids that accumulated with the incubation of larger amounts of $18: 2$ as trilinolein were found to consist of both cis and trans isomers. With $0.86 \mathrm{mg} \mathrm{I} 8: 2 / \mathrm{ml}$ rumen contents the trans-1 $\mathrm{I}$ isomer made up $70-80 \%$ of the total $\mathrm{C}_{18}$ monoene at first, decreasing to $55-60 \%$ of the total $\mathrm{C}_{18}$ monoenes by the end of the incubation. With $1.27 \mathrm{mg} 18: 2 / \mathrm{ml}$ rumen contents the trans-II isomer comprised a minimum of $64 \%$ of the total $\mathrm{C}_{18}$ monoene and reached a maximum of $85 \%$ of the total $\mathrm{C}_{18}$ monoene by the end of the incubation period. With the higher concentrations of trilinolein there was at the end of the incubation period, in addition to the trans-II isomer another, unidentified, trans isomer. The $c$ is isomers consisted largely of cis-9, and cis-I I monoenes, although during incubation an unidentified cis isomer could be detected which in some instances accounted for between one-third and one-half of the total cis isomers present.

\section{Experiments in vivo}

The percentage composition of the rumen free fatty acid fractions before and after infusion of free 'linoleic acid', together with the fatty acid composition of the triglycerides circulating in the plasma, are shown in Table 4. As a result of the infusion of the free 'linoleic acid' the proportion of total $18: 1$ in the rumen free fatty acid fraction by the 24th hour after infusion was markedly increased and the proportions of $16: 0$ and $18: 0$ considerably decreased; the amount of unchanged I $8: 2$ accounted for some $4 \%$ of the total fatty acids present. Although the main $\mathrm{C}_{18}$ monoenoic fatty acid present in the rumen free fatty acid fraction before infusion was the trans-II monoene, the $c i s-18:$ I isomers constituted about $30 \%$ of the total I8: I present; the main cis-monoene present could be identified as the cis-9 isomer. After infusion, the increase in the proportion of $18: \mathrm{I}$ in the rumen free fatty acids consisted predominantly of the trans- $\mathrm{I}$ isomer. The main changes in the fatty acid composition of the plasma triglycerides following the infusion of free 'linoleic acid' into the rumen were similar to the changes in the free fatty acid fraction of

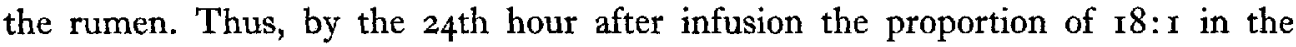
plasma triglycerides had increased considerably and the proportions of $16: 0$ and I8:0 had considerably decreased. Furthermore, $\mathrm{C}_{18}$ cis-9 monoene: $\mathrm{C}_{18}$ trans-1 I 
monoene ratio in the triglyceride fraction of the plasma was about 4.5 before infusion, and by the 24 th hour after infusion the ratio had decreased to less than 0.8 .

Little change was observed in the total fatty acid composition of the free fatty acids in the rumen $24 \mathrm{~h}$ after the infusion of maize oil into the rumen of the sheep. Thus, by the 24th hour after the infusion, I6:0 and I8:0 still accounted for about $85 \%$ of the total fatty acids present in the free fatty acid fraction. In the plasma triglycerides the proportion of $18: 0$ had increased by the $24^{\text {th }}$ hour after infusion and this was accompanied by a decrease in the proportions of $16: 0$ and $18: 1$. There was little change in cis:trans isomers of the total $\mathrm{C}_{18}$ monoenes in either the rumen free fatty acids or the plasma triglycerides following the infusion of maize oil into the rumen.

\section{DISCUSSION}

These experiments indicate that, irrespective of the concentration of linoleic acid used, there are obvious and distinct differences in the extent of biohydrogenation and in the nature of the intermediates produced during the hydrogenation of linoleic acid when supplied in the free or esterified form. Therefore, when the rumen contents were incubated in vitro with trilinolein, the biohydrogenation was always greater than when approximately equivalent amounts of linoleic acid were presented as the free acid. When the formation of $18: 0$ from trilinolein is compared with that from linoleic acid, at the lowest concentration of $18: 2,65 \%$ of $18: 2$ added in the form of the free acid was hydrogenated to $18: 0$, compared with about $77 \%$ when added as the triglyceride; similarly at the next highest concentration of $18: 2$ added only $15 \%$ of $18: 2$ added as the free acid was converted into $18: 0$, compared with about $52 \%$ when added as the triglyceride.

Whereas the $\mathrm{C}_{18}$ monoenoic acid fraction that accumulated during the in vitro incubations of free linoleic acid consisted entirely of the trans-I I isomer (Table I), the $\mathrm{C}_{18}$ monoenoic acid that accumulated during the incubation of the higher concentrations of trilinolein consisted of both cis and trans isomers (Table 3); insufficient amounts of the monoenoic acids were present at the lowest concentration of trilinolein to permit complete analysis. With trilinolein as substrate, the transmonoene consisted largely of the trans-II isomer but the cis-monoene was composed of three main components; generally, the cis-monoenes accounted for about $25 \%$ of the total monoenes present, which is similar to the proportion of the $\mathrm{C}_{18}$ cis-monoenoic fatty acids found in the rumen contents of grazing ruminants (Ward et al. 1964). The changes in the proportions of the main $\mathrm{C}_{18}$ monoenoic isomets during the in vitro incubations were similar to those found in in vivo intraruminal infusions of the sheep with free or esterified 'linoleic acid'. Following the in vivo infusion of free 'linoleic acid' into the rumen of sheep, the increase in trans- $: c i s-\mathrm{C}_{18}$ monoenes produced in the rumen was accompanied by a five- to sixfold increase in trans-: cis- $\mathrm{C}_{18}$ monoenes in the plasma triglycerides. When the same amount of linoleic acid in the form of maize oil was infused into the rumen of sheep, no change could be detected in the proportions of cis- and trans- $\mathrm{C}_{18}$ monoenoic isomers in the rumen or plasma triglycerides. As the plasma triglycerides are now known to be the sole precursors 
of the $C_{18}$ fatty acids secreted in the milk fat (Annison, Linzell, Fazakerley $\&$ Nichols, ${ }^{1967}$ ), the composition of the $\mathrm{C}_{18}$ monoenoic fatty acids of the milk fat would be affected as a consequence.

It is now generally accepted that $\mathrm{x} 8: \mathrm{I}$ trans-I $\mathrm{I}$ is an important intermediate in the pathway of biohydrogenation of linoleic acid to $18: 0$ (Dawson \& Kemp, 1969; Viviani, 1970). It is probable that the biohydrogenation of linoleic acid to $x 8: 0$ involves two microbial groups: those that hydrogenate linoleic acid to $18: I$ and those that hydrogenate I8: I to 18:0 (Polan, McNeill \& Tove, 1964). Polan et al. (1964) have provided evidence to suggest that high concentrations of linoleic acid completely inhibit the conversion of $18: \mathrm{I}$ into $\mathrm{I} 8: 0$. Our results are consistent with this hypothesis, but suggest that factors other than the added $18: 2$ may be involved in this process; the inhibition of the conversion of $\mathrm{I} 8$ : I into $18: 0$ persists for some time after the concentration of the $18: 2$ substrate has been reduced to a negligible amount. When trilinolein was incubated with rumen liquor the rate of hydrolysis of triglyceride may have been insufficient to saturate the hydrogenating system with free $18: 2$, but this may have taken place when free linoleic acid was the substrate. Alternatively it is possible that rumen micro-organisms are adapted to metabolize and tolerate csterified fatty acids to a greater extent than free fatty acids; unesterified fatty acids make up only a small proportion of dietary lipids when compared with those in the esterified form (Lough, I969). It has already been shown that biohydrogenation of glycerol-bound unsaturated fatty acids must be preceded by hydrolysis of the ester linkage. Under normal conditions it appears that, although high rates of lipolysis are known to occur in the rumen (Hawke \& Silcock, I970), these rates do not result in a rate of liberation of free fatty acids sufficient to affect the extent of biohydrogenation.

There was a consistently high proportion of the $18: 1$ cis-9 isomer in the $\mathrm{C}_{18}$ monoenoic acid fraction during the biohydrogenation of trilinolein-derived linoleic acid but none with free linoleic acid; therefore the mechanism of biohydrogenation of trilinolein-derived linoleic acid may differ from that for free linoleic acid. Although more evidence has been obtained from experiments involving linoleic acid rather than trilinolein, the central importance of the trans-I I isomer in the biohydrogenation of $\mathrm{C}_{18}$ polyunsaturated fatty acids is now generally accepted (Dawson \& Kemp, 1969; Viviani, 1970). The biohydrogenation of both linoleic acid and oleic acid was shown by Wilde \& Dawson (I966) to require co-factors present in the cell-free supernatant fraction of rumen fluid, and it was suggested that the absence of these co-factors may be responsible for the accumulation of acids involved in less important, subsidiary pathways by blocking the main pathway of biohydrogenation. This is unlikely in our experiments; all measured properties of the in vitro fermentation $(\mathrm{pH}$, volumes and proportions of gases produced and volatile fatty acid production) were apparently the same in the trilinolein, linoleic acid and control vessels. However, the possibility of alterations in the rumen microbial populations resulting from the presence of linoleic acid either in the free or esterified form cannot be excluded, as it is known that polyunsaturated fatty acids are not without effect on certain aspects of fermentation in the rumen (Czerkawski, 1967; Demeyer \& Henderickx, 1967). 
The observation that high amounts (up to $50 \%$ of the total $18: 2$ added) of cis- 9 , trans-I I conjugated diene accumulated when the main end-product of the hydrogenation of free linoleic acid was I8: I rather than $18: 0$, is further evidence that the hydrogenation of free linoleic acid may follow a pathway different from that of trilinolein-derived linoleic acid. The relationship between the conjugated diene and the trans-I I monoene was similar to that of a product and its precursor. There was no accumulation of this diene when hydrogenation of trilinolein-derived linoleic acid was inhibited; and its concentration in the rumen contents did not exceed the normal concentration.

The effectiveness of rumen biohydrogenation when fats or fatty acids are added to diets which contain adequate amounts of fat has been questioned (Steele $t$ t al. I 97 I ; Macleod et al. 1972). Although the rate of release of free fatty acids by hydrolysis of esterified substrates by the rumen micro-organisms in vitro may be fairly rapid, in normal conditions in vivo it is relatively slow. In conditions where a readily available source of esterified fatty acids (e.g. soya-bean or safflower oil) is present, the initial rate of release of the fatty acids would be considerably greater and may affect rumen metabolism. Results from these in vitro incubations may explain the differences in biohydrogenation observed when the diets of ruminants are supplemented with polyunsaturated fatty acids in either the free or the esterified form and the subsequent effect of these supplemented diets upon plasma triglyceride composition (Steele et al. 1971).

The authors would like to thank Miss A. S. Wallace for her skilled technical assistance.

\section{REFERENCES}

Annison, E. F., Linzell, J. L., Fazakerley, S. \& Nichols, B. W. (1967). Biochem. F. ro2, 637.

Chang, T.-C. L. \& Sweeley, C. C. (1962). F. Lipid Res. 3, I70.

Christie, W. W., Noble, R. C. \& Moore, J. H. (1970). Analyst, Lond. 95, 940.

Czerkawski, J. W. (1966). Br. 7. Nutr. 20, 833 .

Czerkawski, J. W. (1967). Br. F. Nutr. 21, 865.

Czerkawski, J. W. \& Breckenridge, G. (1969). Br. F. Nutr. 23, 5 r.

Dawson, R. M. C. \& Kemp, P. (1969). In Physiology of Digestion and Metabolism in the Ruminant p. 504 [A. T. Phillipson, editor]. Newcastle-upon-Tyne: Oriel Press.

Demeyer, D. I. \& Henderickx, H. K. (1967). Biochim. biophys. Acta $\mathbf{3 3 7}, 484$.

Garton, G. A. (1965). In Physiology of Digestion in The Ruminant p. 390 [R. W. Dougherty, editor]. London: Butterworths.

Hawke, J. C. \& Silcock, W. R. (1970). Biochim. biophys. Acta 218, 201.

Lough, A. K. (1 969). In Physiology of Digestion and Metabolism in the Ruminant p. 519 [A. T. Phillipson, editor]. Newcastle-upon-Tyne: Oriel Press.

McDougall, E. I. (1948). Biochem. F. 43, 99.

Macleod, G. K., Wood, A. S. \& Yao, Y. T. (1972). F. Dairy Sci. 55, 446.

Moore, J. H., Noble, R. C. \& Steele, W. (1968). Br. F. Nutr. 22, 68I.

Moore, J. H., Noble, R. C., Steele, W. \& Czerkawski, J. W. (I969). Br. F. Nutr. 23, 869.

Moore, J. H. \& Williams, D. L. (1963). Can.F. Biochem. Physiol. 41, r821.

Moore, J. H. \& Williams, D. L. (1966). Biochim. biophys. Acta 125, $35^{2}$.

Morris, L. J. (1966). F. Lipid Res. 7, 7 17.

Nelson, G. J. \& Freeman, N. K. (1959). F. biol. Chem. 234, I 375.

Noble, R. C., Steele, W. \& Moore, J. H. (1 969). F. Dairy Res. 23, $7 \circ 9$.

Polan, C. E., McNeill, J. J. \& Tove, S. B. (1964). F. Bact. 88, 1056.

Steele, W., Noble, R. C. \& Moore, J. H. (1971). F. Dairy Res. 38, 49.

Viviani, R. (I970). Adv. Lipid Res. 8, 267.

Ward, P. F. V., Scott, T. W. \& Dawson, R. M. C. (1964). Biochem. F. 92, 60.

Wilde, P. F. \& Dawson, R. M. C. (1966). Biochem. F. 98, 469 . 